\title{
Clinical Study \\ Clinical and Microbiological Profile of HIV/AIDS Cases with Diarrhea in North India
}

\author{
Arun Kumar Jha, ${ }^{1}$ Beena Uppal,, Sanjim Chadha, ${ }^{1}$ Preena Bhalla, ${ }^{1}$ Roumi Ghosh, ${ }^{1}$ \\ Prabhav Aggarwal, ${ }^{1}$ and Richa Dewan ${ }^{2}$ \\ ${ }^{1}$ Department of Microbiology, Maulana Azad Medical College, University of Delhi, Bahadur Shah Zafar Marg, \\ New Delhi 110002, India \\ ${ }^{2}$ Department of Medicine, Maulana Azad Medical College, University of Delhi, Bahadur Shah Zafar Marg, New Delhi 110002, India
}

Correspondence should be addressed to Arun Kumar Jha, dr_jhauc2k@yahoo.co.in

Received 24 September 2012; Revised 30 November 2012; Accepted 3 December 2012

Academic Editor: Nat F. Brown

Copyright (C) 2012 Arun Kumar Jha et al. This is an open access article distributed under the Creative Commons Attribution License, which permits unrestricted use, distribution, and reproduction in any medium, provided the original work is properly cited.

Intestinal infections are a significant cause of morbidity and mortality in people living with HIV/AIDS (PLWHA) especially in developing countries. The present study was conducted to assess the clinical and microbiological spectrum in HIV/AIDS cases with diarrhea and to correlate the occurrence of such pathogens with stool characters, HIV seropositivity status, and CD4 counts. Stools from $154 \mathrm{HIV}$ seropositive subjects and $50 \mathrm{HIV}$ negative controls were examined by direct microscopy, fecal cultures, and serological tests (Clostridium difficile Toxin A, Cryptosporidium antigen, and Entamoeba histolytica antigen ELISA). CD4 T cell enumeration was done using FACS count (Becton Dickinson). The study showed a male preponderance (112 males and 42 females). Weakness, abdominal pain, and anorexia were the most common symptoms. Coccidian parasites were the most common cause of diarrhea in HIV seropositive cases. C. parvum was seen in $60.42 \%$ while Isospora belli in $9.03 \%$. Amongst the bacterial pathogens $C$. difficile was detected in $18.06 \%$, diarrheagenic Escherichia coli in $11.11 \%$, and Shigella spp. in $2.78 \%$. Pathogen isolation rates were more in HIV seropositive cases and subjects with low CD4 T lymphocyte counts. Regular monitoring of CD4 T lymphocyte counts and screening for enteric pathogens will help improve the quality of life for PLWHA.

\section{Introduction}

Infection with human immunodeficiency virus (HIV) imposes monumental suffering on afflicted individuals, and in the developing world in particular it places a great burden on the medical system [1]. For a poverty-stricken and disease-ravaged country like India, the scourge of HIV/AIDS is most unfortunate. One of the major health problems among HIV seropositive patients due to a waning immunity is superimposed opportunistic infections, and it is often seen that during the course of the disease patients become a microbial zoo $[2,3]$. Patients may have several such concurrent infections, resulting in clinical conditions that pose diagnostic and therapeutic challenges [4-6].

Diarrhea is one such very common clinical condition in HIV/AIDS and has been included as a criterion for defining a case of AIDS [7, 8]. Episodes of diarrhea may be acute and brief, intermittent or recurrent, or, in some cases, chronic and severe. Diarrhea may significantly diminish patients' quality of life and if it persists may cause dehydration, poor nutrition, and weight loss $[9,10]$. Diarrhea has been associated with $50 \%$ of HIV/AIDS patients in the developed world and in up to $100 \%$ of patients residing in developing countries [11-13].

The causes of diarrhea in AIDS can be infectious or noninfectious. Noninfectious diarrhea could be due to ARTrelated adverse effects and HIV enteropathy [14]. Several studies have shown that infectious diarrhea in HIV/AIDS is caused by a variety of pathogens including parasites, bacteria, viruses, and fungi. There is no specific combination of intestinal pathogens in HIV-associated diarrhea, and the etiological agents vary from patient to patient and from country to country depending on the geographical distribution, endemicity, seasonal variation of the enteric pathogens, and also on the immune status of the patient [15-18]. A diagnostic workup including direct microscopy, 
fecal cultures, and serological tests to detect specific antigen and/or specific antibody is needed for each patient as most of these infectious agents are treatable.

With the previous background in mind, this study was undertaken to assess the clinical and microbiological spectrum in HIV/AIDS cases with diarrhea registered in Delhi's largest tertiary care hospital catering to patients not only from Delhi but also from the neighboring states of Uttar Pradesh, Haryana, Punjab, and Himachal Pradesh. The motive was to understand the microbial etiologies of diarrhea in such cases so that appropriate medical investigations, specific therapy, and adequate nutritional counseling can help reduce the socioeconomic and medical costs for this disease in our country.

\section{Materials and Methods}

2.1. Study Population. One hundred and fifty-four HIV seropositive adult subjects with diarrhea attending the ART clinic of Lok Nayak Hospital affiliated to Maulana Azad Medical College, New Delhi, India, were recruited for this study irrespective of their ART status. Only those HIV seropositive subjects with diarrhea were enrolled who had not received any specific antidiarrheal therapy in the last two weeks. Fifty age- and sex-matched randomly selected adult HIV seronegative subjects with symptoms of diarrhea were also enrolled as control group who come for routine examinations of their stool samples to the microbiology laboratory of Maulana Azad Medical College, New Delhi. Subjects who had received any specific antidiarrheal therapy in the last two weeks and/or were not sure of their HIV status were excluded from the control group.

2.2. Study Design. This study was conducted from April 2008 to June 2011. This was a cross-sectional analysis to determine the clinical and microbiological profile of diarrhea in AIDS cases and HIV seronegative control subjects. At enrollment informed consent was obtained and each study participant was asked to complete a questionnaire which consisted of sociodemographic and personal details, history of diarrheal episodes, clinical signs and symptoms, and so forth. Fecal specimens were requested from all the participants. Samples were collected in a clean wide mouth screw capped disposable plastic container and transported to the microbiology laboratory by the patients themselves on the same day avoiding any unnecessary delay.

2.3. Definition of Diarrhea. Diarrhea was defined as the passage of three or more loose or watery bowel movements in a 24-hour period. Acute diarrhea was defined as diarrhea which lasted 7 days or less at the time of presentation. Persistent diarrhea was defined as diarrhea which lasted for more than 7 days but less than 14 days at presentation. Diarrhea was called chronic if it lasted for more than 14 days [19].

2.4. Laboratory Examination. All fecal specimens were subjected to a battery of microbiological examinations. The specimens were stored at 4 degree Celsius if there was a delay in processing. The color, consistency, and presence of blood/mucus/worms in the stool specimens were recorded. A loopful of sample was emulsified in a drop of saline and Lugol's iodine on a slide and examined under the microscope for the presence of trophozoites of Entamoeba histolytica, Giardia lamblia, RBCs, pus cells, helminthic ova, and cyst. Stool smears were prepared, heat fixed, and stained by the Gram's, Kinyoun's (modified acid fast stain), and trichrome stain. All samples were cultured directly as well as after enrichment in Selenite F Broth and Alkaline Peptone Water onto Xylose Lysine Deoxycholate agar and Bile Salt Agar respectively. Specialized selective media, charcoal cefoperazone deoxycholate agar (CCDA) was used for isolation of Campylobacter jejuni which was incubated in a microaerophilic environment at $42^{\circ} \mathrm{C}$ for $48 \mathrm{hrs}$. For isolation of Aeromonas spp. and Yersinia enterocolitica, stool samples were cultured on Aeromonas selective media and Yersinia selective media, respectively. The organisms were identified on the basis of their colony characteristics, biochemical tests, and serologically by slide agglutination test using commercially available specific antisera. Detection of $C$. difficile Toxin A, Cryptosporidium antigen, and E. histolytica antigen in stool samples was done by commercially available Enzyme Immunoassay kits.

The CD4 T lymphocyte count of all participants was determined by the FACS count by Becton Dickinson.

2.5. Statistical Analysis. To study the correlation between the frequencies of enteric pathogens and stool consistency the Kruskal-Wallis test was applied. To study the relation between the isolation rate of intestinal pathogens and the HIV seropositivity status, and CD4 T lymphocyte counts, the chi-square test and the Fisher's exact test were used.

\section{Results}

Out of the one hundred and fifty-four HIV seropositive subjects recruited $112(72.73 \%)$ were males and $42(27.27 \%)$ were females. $64.94 \%$ of the study subjects were in the age group 26-35 years, the sexually active age group. The mean age of the participants in our study was 32.36 years, and the age ranged between 18 and 68 years. Majorities (23\%) of our subjects were illiterate, and $21.7 \%$ had received education up to the primary school level.

Table 1 shows the distribution of cases as per the clinical symptoms recorded at the time of recruitment of cases. Weakness, abdominal pain, and anorexia were the most common symptoms associated with diarrhea in HIV seropositive cases while abdominal pain, vomiting, and fever were the most common complaints in the HIV seronegative control group.

Out of 154 HIV seropositive cases enrolled, only 144 participants submitted their fecal specimens. Majority (60.39\%) of the HIV seropositive cases had chronic diarrhea (Table 2) while most (72\%) of the HIV seronegative subjects had acute diarrhea.

Table 3 shows the enteropathogens isolated in relation to stool consistency. Certain pathogens (C. parvum and I. belli) 
TABLE 1: Clinical symptoms of cases with diarrhea.

\begin{tabular}{lccc}
\hline Symptoms & $\begin{array}{c}\text { HIV seropositive } \\
\text { No. (percentage) } \\
(n=154)\end{array}$ & $\begin{array}{c}\text { HIV seronegative } \\
\text { No. (percentage) } \\
(n=50)\end{array}$ & $\begin{array}{c}P \text { value } \\
\text { (chi-square test) }\end{array}$ \\
\hline Weakness & $100(64.93 \%)$ & $35(30.00 \%)$ & 0.0001 \\
Abdominal pain & $95(61.69 \%)$ & $7(14.00 \%)$ & 0.372 \\
Anorexia & $80(51.95 \%)$ & $27(54.00 \%)$ & 0.0001 \\
Fever & $30(19.48 \%)$ & $24(48.00 \%)$ & 0.0001 \\
Nausea & $25(16.23 \%)$ & $30(60.00 \%)$ & 0.0001 \\
Vomiting & $21(13.64 \%)$ & $5(10.00 \%)$ & 0.0001 \\
Blood in the stools & $10(6.50 \%)$ & & 0.608 \\
\hline
\end{tabular}

TABLE 2: Duration of diarrhea in study subjects.

\begin{tabular}{lccc}
\hline Duration & $\begin{array}{c}\text { HIV seropositive } \\
\text { No. (percentage) } \\
(n=154)\end{array}$ & $\begin{array}{c}\text { HIV seronegative } \\
\text { No. (percentage) } \\
(n=50)\end{array}$ & $\begin{array}{c}P \text { value } \\
(\text { chi-square test) }\end{array}$ \\
\hline$<1$ week (acute diarrhea) & $32(20.78 \%)$ & $36(72.00 \%)$ & 0.0001 \\
$1-2$ weeks (persistent diarrhea) & $29(18.83 \%)$ & $8(16.00 \%)$ & 0.810 \\
$>$ 2weeks (chronic diarrhea) & $93(60.39 \%)$ & $6(12.00 \%)$ & 0.0001 \\
\hline
\end{tabular}

were more frequently detected in watery stools, and this was found to be statistically significant $(P$ value $<0.05)$, whereas the bacterial pathogens ( $C$. difficile, diarrheagenic $E$. coli, and Shigella spp.) were found to be significantly more frequent in the formed stools $(P$ value $<0.05)$. Coccidian parasites were the most common cause of diarrhea in HIV seropositive cases, C. parvum being detected in $60.42 \%$ cases. Amongst the bacterial pathogens $C$. difficile topped the list with $18.06 \%$ cases showing $C$. difficile positivity. Candida albicans was isolated in $25.69 \%$ of our cases.

Table 4 shows the frequency of intestinal pathogens in relation to the HIV status of the study cases. C. parvum, $C$. difficile, and C. albicans were found to be significantly more common in the HIV-seropositive study cases than the HIVnegative control group $(P$ value $<0.05)$.

Overall the rate of isolation of pathogens causing diarrhea in HIV was higher in HIV seropositive individuals with CD4 counts less than 200 cells $/ \mu \mathrm{L}$ as compared to HIV seropositive individuals with CD4 counts more than 200 cells $/ \mu \mathrm{L}$. However, the isolation rate was significantly higher for C. parvum, I. belli, C. difficile, and C. albicans only $(P$ value $<0.05)$ in patients with CD $4<200$ cells $/ \mu \mathrm{L}$ as shown in Table 5.

\section{Discussion}

Diarrhea is the second leading cause of hospital visits in the developing nations in patients with HIV/AIDS [20]. The etiology of diarrhea in AIDS is multifactorial. Expectedly infectious etiologies lead the list in developing nations in contrast to noninfectious etiologies in developed nations. There are many studies on the etiological agents of diarrhea in HIV/AIDS from various parts of North India [21-23]. But there are very few reports on the diarrheal pathogens isolated in HIV/AIDS cases in relation to CD4 T lymphocyte counts and stool characteristics from New Delhi. Our study divulges the infectious etiological agents of diarrhea in HIV/AIDS patients from New Delhi's busiest and largest tertiary care hospital located at the heart of the city. This study also looks into the correlation of diarrheal agents isolated with HIV seropositivity status, stool characteristics, and CD4 T lymphocyte counts.

The present study shows a preponderance of male cases (112 males out of 154 cases) with a male-to-female ratio of 2.66: 1 as shown by other studies conducted on HIV-positive cases with diarrhea in India [24]. Predominance of male cases may be due to their migration to the metropolitan cities (Delhi being one of such type) in search of work. Staying away from their spouse for longer periods and males being promiscuous by habit resulted in acquiring HIV infection. Moreover, the male preponderance might have been due to the fact that in the existing social milieu in India, females do not seek medical care fearing ostracism and loss of family support. The mean age of the participants in our study was 32.36 years with the most common age group being 2635 years. This section of the population is more affected because they are sexually more active. Similar results were obtained in a study from South India where median age of HIV seropositives with diarrhea was 34 and the mean age was 36 years $[25]$.

The most frequent clinical findings in the HIV seropositive cases with diarrhea in our study were weakness $(64.93 \%)$, abdominal pain (61.69\%), and anorexia (51.95\%). This is similar to what has been reported by Chhin et al. from Cambodia where abdominal pain (90.3\%), fever $(86.7 \%)$, and weakness $(80 \%)$ were the most common presenting complaints in HIV-positive cases with diarrhea [26]. Weakness and anorexia were the symptoms found to be significantly $(P$ value $<0.05)$ associated with diarrhea in HIV-positive cases as compared to the HIV seronegative 
TABLE 3: Frequency of enteric pathogens isolated in relation to stool consistency $(n=144)$.

\begin{tabular}{|c|c|c|c|c|c|}
\hline Organism & $\begin{array}{l}\text { Formed } \\
(n=30)\end{array}$ & $\begin{array}{l}\text { Semiformed } \\
\quad(n=68)\end{array}$ & $\begin{array}{c}\text { Loose/watery } \\
\quad(n=46)\end{array}$ & $\begin{array}{c}\text { Total } \\
(n=144)\end{array}$ & $P$ value* \\
\hline C. parvum & $11(36.67 \%)$ & $39(57.35 \%)$ & $37(80.43 \%)$ & $87(60.42 \%)$ & 0.0001 \\
\hline I. belli & $1(3.33 \%)$ & $4(5.88 \%)$ & $8(17.39 \%)$ & $13(9.03 \%)$ & 0.022 \\
\hline Cyclospora spp. & 0 & 0 & $2(4.35 \%)$ & $2(1.39 \%)$ & - \\
\hline Microsporidium spp. & 0 & 0 & $1(2.17 \%)$ & $1(0.69 \%)$ & - \\
\hline E. histolytica & $2(6.67 \%)$ & $5(7.35 \%)$ & 0 & $7(4.86 \%)$ & 0.121 \\
\hline G. lamblia & 0 & $3(4.41 \%)$ & 0 & $3(2.08 \%)$ & - \\
\hline A. lumbricoides & $3(10.00 \%)$ & $1(1.47 \%)$ & $1(2.17 \%)$ & $5(3.47 \%)$ & 0.125 \\
\hline C. difficile & $15(50.00 \%)$ & $9(13.23 \%)$ & $2(4.35 \%)$ & $26(18.06 \%)$ & 0.0001 \\
\hline Diarrheagenic E. coli & $10(33.34 \%)$ & $5(7.35 \%)$ & $1(2.10 \%)$ & $16(11.11 \%)$ & 0.0001 \\
\hline Shigella spp. & $3(10.00 \%)$ & $1(1.47 \%)$ & 0 & $4(2.78 \%)$ & 0.018 \\
\hline C. albicans & $10(33.34 \%)$ & $24(35.29 \%)$ & $3(6.52 \%)$ & $37(25.69 \%)$ & 0.002 \\
\hline
\end{tabular}

${ }^{*} P$ value calculation using Kruskal-Wallis test.

TABLE 4: Frequency of enteric pathogens in relation to the HIV status of study subjects.

\begin{tabular}{|c|c|c|c|}
\hline Organism & $\begin{array}{l}\text { HIV seropositive cases } \\
\quad(n=144)\end{array}$ & $\begin{array}{l}\text { HIV seronegative subjects } \\
\qquad(n=50)\end{array}$ & $P$ value (chi-square test) \\
\hline C. parvum & 87 (60.42\%) & $1(2.00 \%)$ & 0.0001 \\
\hline I. belli & $13(9.03 \%)$ & $1(2.00 \%)$ & 0.082 \\
\hline Cyclospora spp. & $2(1.39 \%)$ & 0 & - \\
\hline Microsporidium spp. & $1(0.69 \%)$ & 0 & - \\
\hline E. histolytica & $7(4.86 \%)$ & $1(2.00 \%)$ & 0.343 \\
\hline G. lamblia & $3(2.08 \%)$ & $2(4.00 \%)$ & 0.726 \\
\hline A. lumbricoides & $5(3.47 \%)$ & $1(2.00 \%)$ & $0.514^{*}$ \\
\hline C. difficile & $26(18.06 \%)$ & $3(6.00 \%)$ & 0.040 \\
\hline Diarrheagenic E. coli & $16(11.11 \%)$ & $2(4.00 \%)$ & $0.166^{*}$ \\
\hline Shigella spp. & $4(2.78 \%)$ & 0 & - \\
\hline C. albicans & $37(25.69 \%)$ & $2(4.00 \%)$ & 0.0001 \\
\hline
\end{tabular}

${ }^{*} P$ value calculation using Fisher's exact test.

control group (Table 1). Chronic diarrhea was significantly more $(60.39 \%$; $P$ value $<0.05)$ in the HIV positives than the HIV negatives (Table 2). Another study from North India has reported chronic diarrhea in 69.3\% HIV cases [24]. Vomiting, fever, and nausea were more frequently seen in the HIV seronegative group with diarrhea (association found to be statistically significant; $P$ value $<0.05)$, and most of the subjects in this group had acute diarrhea (36/50; $P$ value $<0.05)$. This may be due to the fact that diarrhea in HIV seronegatives is most probably due to acute infectious causes which is more likely to be associated with fever, nausea, and vomiting. And diarrhea which is chronic in nature, as is seen in the HIV-positive cases, is more likely to be associated with anorexia, weakness, and weight loss.

In our study C. parvum and I. belli were significantly more commonly seen to be associated with watery stools while the bacterial enteropathogens (C. difficile, diarrheagenic E. coli, and Shigella spp.) were more common in the formed stools ( $P$ value $<0.05)$. A study from Zambia reports that infections with C. parvum, I. belli, and G. lamblia are associated with increasing water content of the stool samples in HIV-positive cases with diarrhea
[27]. Higher positivity associated with watery stools could be due to infection with the more invasive and virulent enteropathogens causing more inflammation leading to watery diarrhea and increased shedding. This observation of the consistency of the stools of HIV/AIDS patients could help in the presumptive diagnosis of the intestinal etiological agents and allow parasitological investigation to be targeted at the cases most likely to be found positive.

We found that intestinal parasites are the most common enteric pathogens associated with diarrhea in the North Indian HIV-positive population. A study from Chennai also documents the prevalence of enteric parasites in HIV patients with diarrhea [28]. The microbiological profile seen in our HIV seropositive cases is typical of what has been reported by other Indian studies [29], intestinal coccidian parasites being the most common enteric pathogens isolated amongst which C. parvum was the most frequent $(60.42 \%$ of the cases). Cryptosporidium positivity rate in HIV-positive patients with diarrhea has been reported to be in the range of $5.71 \%-22.8 \%$ by various Indian authors [20-23]. The substantially high Cryptosporidium positivity in our study could be due to the use of more than one method of detection of 
TABLE 5: Frequency of enteropathogens in relation to CD4 counts in HIV seropositive cases $(n=144)$.

\begin{tabular}{lccc}
\hline Organism & $\begin{array}{c}\mathrm{CD} 4<200 \text { cells/ } \mu \mathrm{L} \\
(n=54)\end{array}$ & $\begin{array}{c}\mathrm{CD} 4 \geq 200 \text { cells/ } \mu \mathrm{L} \\
(n=90)\end{array}$ & $P$ value (chi-square test) \\
\hline C. parvum & $47(87.04 \%)$ & $40(44.45 \%)$ & 0.0001 \\
I. belli & $11(20.37 \%)$ & $2(2.23 \%)$ & $0.0001^{*}$ \\
Cyclospora spp. & $2(3.70 \%)$ & 0 & - \\
Microsporidium spp. & $1(1.85 \%)$ & 0 & - \\
E. histolytica & $4(7.41 \%)$ & $3(3.34 \%)$ & $0.403^{*}$ \\
G. lamblia & $2(3.70 \%)$ & $1(1.11 \%)$ & $0.556^{*}$ \\
A. lumbricoides & $3(5.56 \%)$ & $2(2.22 \%)$ & $0.631^{*}$ \\
C. difficile & $14(25.92 \%)$ & $12(13.33 \%)$ & 0.048 \\
Diarrheagenic E. coli & $7(12.96 \%)$ & $9(10.00 \%)$ & 0.594 \\
Shigella spp. & $3(5.56 \%)$ & $1(1.11 \%)$ & $0.148^{*}$ \\
C. albicans & $25(46.30 \%)$ & $12(13.33 \%)$ & 0.0001 \\
\hline
\end{tabular}

${ }^{*} P$ value calculation using Fisher's exact test.

Cryptosporidium, for example, Modified Kinyoun's method and ELISA. It could also be due to the fact that majority of our cases had watery and semiformed stools. Geographical and seasonal variations have also been seen to impact the prevalence of this parasite. Cryptosporidium causes profuse and watery diarrhea in AIDS patients and may produce fluid loss of up to 10 liters per day. Small environmentally resistant oocysts, low infective dose (10-100 oocysts), and oocysts being resistant to disinfectants are some of the factors which impact the epidemiology of Cryptosporidium infection. As no effective cure is available for cryptosporidiosis especially in immunocompromised individuals, it usually has a poor prognosis [2]. The isolation rate of Cyclospora (1.39\%) and Microsporidia $(0.69 \%)$ was quite low in the present study. The reason for this low detection may be that these pathogens are shed intermittently and may not have been present in the fecal samples submitted or may have been probably overlooked by the inexperienced microscopist. Repeated examination of fecal samples is recommended for their detection. The diagnostic methods like transmission electron microscopy, histochemistry, immunofluorescent antibody staining, and PCR-based methods should improve and simplify their detection in clinical samples [30, 31]. Some authors have reported a low percentage of Microsporidium (1.69\%) and Cyclospora (1.69\%) while others have reported a high percentage $(41 \%$ and $2.6 \%)$ from India $[28,32]$. Ascaris lumbricoides was seen in $5.56 \%$ of our cases probably due to expulsion in the feces with repeated flushing of intestinal contents in diarrhea. G. lamblia and E. histolytica were found in $3.7 \%$ and $7.41 \%$ of the cases. The presence of these parasites reflects poor environmental hygiene and sanitation. They have been seen to cause chronic diarrhea in immunocompromised hosts.

In our study $C$. difficile was the most common bacterial pathogen identified (18.06\%). This points out that C. difficile is a common enteric pathogen responsible for diarrhea in HIV-infected patients since they are subjected to repeated antibiotic therapy due to opportunistic infections, and clinicians should keep this pathogen as a differential diagnosis when searching for the cause of diarrhea in HIV/AIDS especially in developing countries like ours where antibiotic access is unregulated. A study from Nigeria has reported the prevalence of C. difficile infection to be $43 \%$ and $14 \%$ for HIV-positive inpatients and outpatients, respectively [33]. C. albicans was seen in $25.69 \%$ cases in our study. This may be due to low immunity and frequent use of antibiotics. A high rate of isolation of C. albicans (36\%) in HIV-positive cases with diarrhea has been reported in a previous study from our department in past [34].

C. parvum, C. difficile, and C. albicans were significantly more common in the HIV-positive group than the HIVnegative control group $(P$ value $<0.05)$. This suggests that immunodeficient state in AIDS makes PLWHA more susceptible to such infections, and once established they are not able to prevent the proliferation or clear the infecting agent. This finding corresponds well with other studies [8, 27] and is a common observation in HIV/AIDS.

In our study HIV seropositive cases with CD4 counts $<200$ cells $/ \mu \mathrm{L}$ had a higher rate of infection with certain pathogens, and this was found to be statistically significant as shown in Table 5 . The most common amongst these pathogens were the opportunistic gastrointestinal parasites, C. parvum, and I. belli which cause infection when there is a downregulation of the immune system as is seen with decreasing CD4 levels. The isolation rates decreased with the increase in the CD4 cell counts due to immune reconstitution seen after effective administration of HAART. This is in accordance with the study conducted by Tuli et al. who found an inverse relationship between isolation rates of enteric pathogens and CD4 counts [24].

\section{Conclusions}

The present study has revealed that the majority of HIVpositive cases had chronic diarrhea, coccidian parasites were the major pathogens incriminated in causation of this diarrhea, and cases with watery stools had a higher rate of pathogens detected. Isolation rates were also higher in those with CD4 counts $<200$ cells $/ \mu \mathrm{L}$. 
To sum up our study highlights the importance of early diagnosis of intestinal pathogens causing diarrhea in HIV/AIDS as this would contribute to significantly reducing the morbidity and mortality associated with it. This study also emphasizes the need to establish appropriate diagnostic facilities for identification of enteric organisms in the stool specimens and their ready availability at the peripheral health centers in our country where the HIV/AIDS disease burden is concentrated. This is vital as a delay in transportation of stool specimens to the far-off urban laboratories, and lack of motivation on the part of the unaware patient plays a major role in the case fatalities associated with this disease.

\section{Acknowledgments}

The authors would like to acknowledge the technical assistance provided by Mrs. Kamlesh. They would also like to thank Dr. Sanjeev Saini for helping them with the statistical analysis.

\section{References}

[1] L. Elfstrand and C. H. Florén, "Management of chronic diarrhea in HIV-infected patients: current treatment options, challenges and future directions," HIV/AIDS - Research and Palliative Care, vol. 2, pp. 219-224, 2010.

[2] D. R. Arora and B. Arora, "AIDS- Associated parasitic diarrhoea," Indian Journal of Medical Microbiology, vol. 27, no. 3, pp. 185-190, 2009.

[3] A. R. B. Rossit, M. T. G. de Almeida, C. A. M. Nogueira et al., "Bacterial, yeast, parasitic, and viral enteropathogens in HIVinfected children from São Paulo State, Southeastern Brazil," Diagnostic Microbiology and Infectious Disease, vol. 57, no. 1, pp. 59-66, 2007.

[4] O. Suthienkul, P. Aiumlaor, K. Siripanichgon et al., "Bacterial causes of aids-associated diarrhea in Thailand," Southeast Asian Journal of Tropical Medicine and Public Health, vol. 32, no. 1, pp. 158-170, 2001.

[5] R. W. Goodgame, "Understanding intestinal spore-forming protozoa: Cryptosporidia, Microsporidia, Isospora, and Cyclospora," Annals of Internal Medicine, vol. 124, no. 4, pp. 429-441, 1996.

[6] R. Modigliani, C. Bories, and Y. Le Charpentier, "Diarrhoea and malabsorption in acquired immune deficiency syndrome: a study of four cases with special emphasis on opportunistic protozoan infestations," Gut, vol. 26, no. 2, pp. 179-187, 1985.

[7] U. Siddiqui, E. J. Bini, K. Chandarana et al., "Prevalence and impact of diarrhea on health-related quality of life in HIV-infected patients in the era of highly active antiretroviral therapy," Journal of Clinical Gastroenterology, vol. 41, no. 5, pp. 484-490, 2007.

[8] R. Amatya, R. Shrestha, N. Poudyal, and S. Bhandari, "Opportunistic intestinal parasites and CD4 count in HIV infected people," Journal of Pathology of Nepal, vol. 1, pp. 118-121, 2011.

[9] K. E. Mönkemüller and C. M. Wilcox, "Investigation of diarrhea in AIDS," Canadian Journal of Gastroenterology, vol. 14, no. 11, pp. 933-940, 2000.

[10] S. R. Framm and R. Soave, "Agents of diarrhea," Medical Clinics of North America, vol. 81, no. 2, pp. 427-447, 1997.
[11] P. D. Smith, T. C. Quinn, W. Strober, E. N. Janoff, and H. Masur, "Gastrointestinal infections in AIDS," Annals of Internal Medicine, vol. 116, no. 1, pp. 63-77, 1992.

[12] R. Colebunders, H. Francis, J. M. Mann et al., "Persistent diarrhea, strongly associated with HIV infection in Kinshasa, Zaire," American Journal of Gastroenterology, vol. 82, no. 9, pp. 859-864, 1987.

[13] H. B. Mayer and C. A. Wanke, "Diagnostic strategies in HIVinfected patients with diarrhea," AIDS, vol. 8, no. 12, pp. 16391648, 1994.

[14] R. D. MacArthur and H. L. DuPont, "Etiology and pharmacologic management of noninfectious diarrhea in HIV-infected individuals in the HAART era," Clinical Infectious Diseases, vol. 55, no. 6, pp. 860-867, 2012.

[15] C. Blanshard, N. Francis, and B. G. Gazzard, "Investigation of chronic diarrhoea in acquired immunodeficiency syndrome. A prospective study of 155 patients," Gut, vol. 39, no. 6, pp. 824-832, 1996.

[16] T. Gumbo, S. Sarbah, I. T. Gangaidzo et al., "Intestinal parasites in patients with diarrhea and human immunodeficiency virus infection in Zimbabwe," AIDS, vol. 13, no. 7, pp. 819821, 1999.

[17] S. V. Kulkarni, R. Kairon, S. S. Sane et al., "Opportunistic parasitic infections in HIV/AIDS patients presenting with diarrhoea by the level of immunesuppression," Indian Journal of Medical Research, vol. 130, no. 1, pp. 63-66, 2009.

[18] X.-M. Chen, J. S. Keithly, C. V. Paya, and N. F. LaRusso, "Cryptosporidiosis," The New England Journal of Medicine, vol. 346, no. 22, pp. 1723-1731, 2002.

[19] National AIDS Control Organisation, Ministry of Health \& Family Welfare, Government of India. Guidelines for prevention and management of common opportunistic infections/malignancies among HIV infected adults and adolescents, 2007, http://nacoonline.org/upload/Policies\%20 \&\%20Guidelines/7-Guidelines\%20for\%20Prevention\%20and $\% 20$ Management $\% 20$ of $\% 20$ common $\% 20$ opportunistic $\% 20$ infections.pdf.

[20] S. V. S. Attili, A. K. Gulati, V. P. Singh, D. V. Varma, M. Rai, and S. Sundar, "Diarrhea, CD4 counts and enteric infections in a hospital-based cohort of HIV-infected patients around Varanasi, India," BMC Infectious Diseases, vol. 6, article 39, 2006.

[21] M. Joshi, A. S. Chowdhary, P. J. Dalal, and J. K. Maniar, "Parasitic diarrhoea in patients with AIDS," National Medical Journal of India, vol. 15, no. 2, pp. 72-74, 2002.

[22] D. N. Lanjewar, C. Rodrigues, D. G. Saple, S. K. Hira, and H. L. Dupont, "Cryptosporidium, Isospora and Strongyloides in AIDS," National Medical Journal of India, vol. 9, no. 1, pp. 1719, 1996.

[23] K. Mohandas, R. Sehgal, A. Sud, and N. Malla, "Prevalence of intestinal parasitic pathogens in HIV-seropositive individuals in Northern India," Japanese Journal of Infectious Diseases, vol. 55, no. 3, pp. 83-84, 2002.

[24] L. Tuli, A. K. Gulati, S. Sundar, and T. M. Mohapatra, "Correlation between CD4 counts of HIV patients and enteric protozoan in different seasons-an experience of a tertiary care hospital in Varanasi (India)," BMC Gastroenterology, vol. 8, article 36, 2008.

[25] K. Ramakrishnan, R. Shenbagarathai, A. Uma, K. Kavitha, R. Rajendran, and P. Thirumalaikolundusubramanian, "Prevalence of intestinal parasitic infestation in HIV/AIDS patients with diarrhea in Madurai City, south India," Japanese Journal of Infectious Diseases, vol. 60, no. 4, pp. 209-210, 2007. 
[26] S. Chhin, J. I. Harwell, J. D. Bell et al., "Etiology of chronic diarrhea in antiretroviral-naive patients with HIV infection admitted to Norodom Sihanouk Hospital, Phnom Penh, Cambodia," Clinical Infectious Diseases, vol. 43, no. 7, pp. 925932, 2006.

[27] P. Kelly, J. Todd, S. Sianongo et al., "Susceptibility to intestinal infection and diarrhoea in Zambian adults in relation to HIV status and CD4 count," BMC Gastroenterology, vol. 9, article 7, 2009.

[28] S. S. Kumar, S. Ananthan, and P. Lakshmi, "Intestinal parasitic infection in HIV infected patients with diarrhoea in Chennai," Indian Journal of Medical Microbiology, vol. 20, no. 2, pp. 8891, 2002.

[29] S. S. Kumar, S. Ananthan, and P. Saravanan, "Role of coccidian parasites in causation of diarrhoea in HIV infected patients in Chennai," Indian Journal of Medical Research, vol. 116, pp. 8589, 2002.

[30] L. S. Mansfield and A. A. Gajadhar, "Cyclospora cayetanensis, a food- and waterborne coccidian parasite," Veterinary Parasitology, vol. 126, no. 1-2, pp. 73-90, 2004.

[31] E. S. Didier and L. M. Weiss, "Microsporidiosis: current status," Current Opinion in Infectious Diseases, vol. 19, no. 5, pp. 485-492, 2006.

[32] A. De, K. Patil, and M. Mathur, "Detection of enteric parasites in HIV positive patients with diarrhea," Indian Journal of Sexually Transmitted Diseases, vol. 30, no. 1, pp. 55-56, 2009.

[33] K. Onwueme, Y. Fadairo, L. Idoko et al., "High prevalence of toxinogenic Clostridium difficile in Nigerian adult HIV patients," Transactions of the Royal Society of Tropical Medicine and Hygiene, vol. 105, no. 11, pp. 667-669, 2011.

[34] B. Uppal, B. Kashyap, and P. Bhalla, "Enteric pathogens in HIV/AIDS from a tertiary care hospital," Indian Journal of Community Medicine, vol. 34, no. 3, pp. 237-242, 2009. 


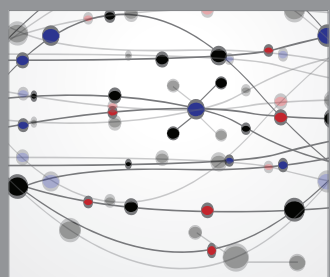

The Scientific World Journal
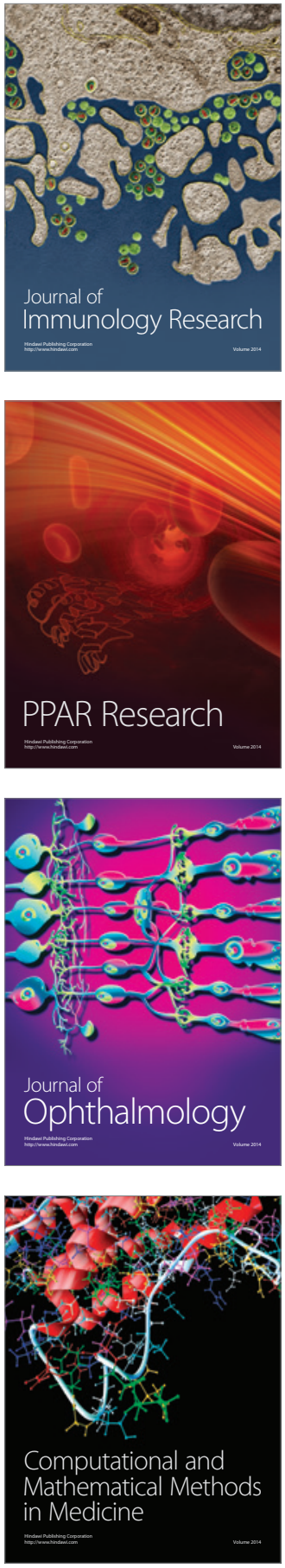

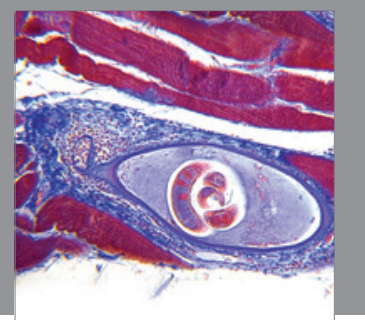

Gastroenterology

Research and Practice
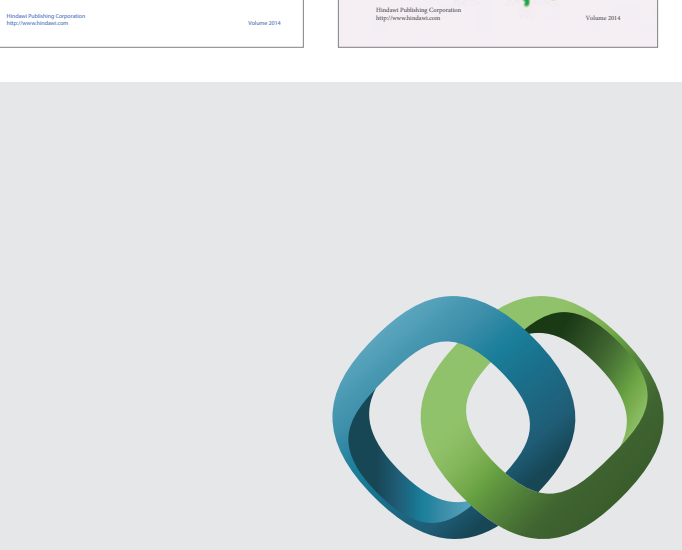

\section{Hindawi}

Submit your manuscripts at

http://www.hindawi.com
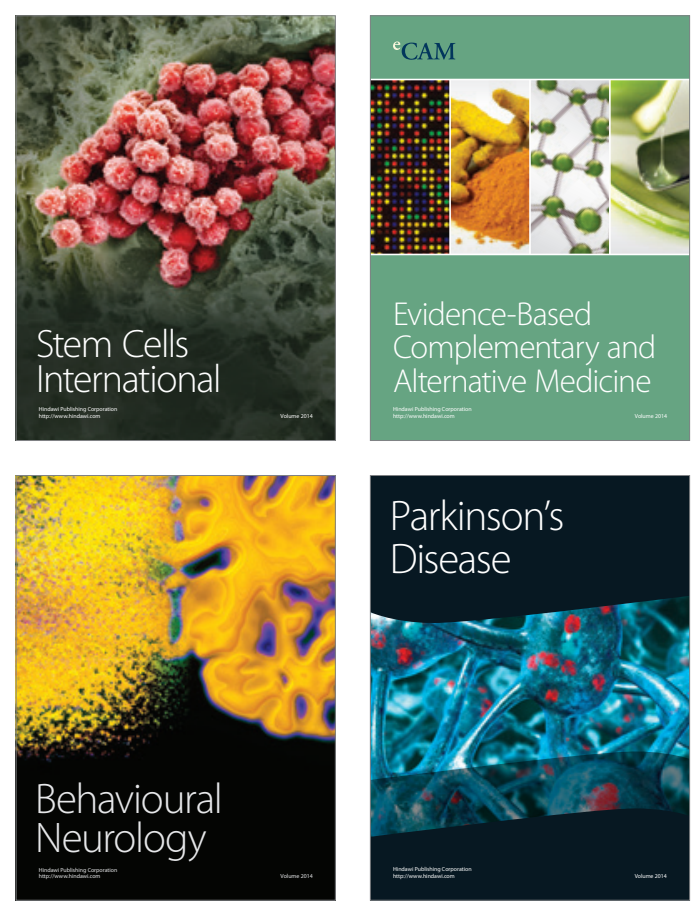

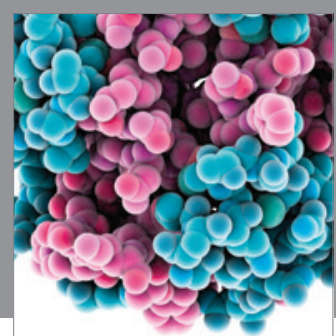

Journal of
Diabetes Research

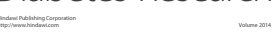

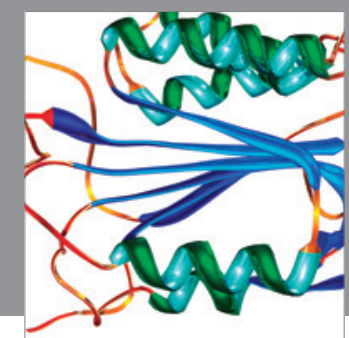

Disease Markers
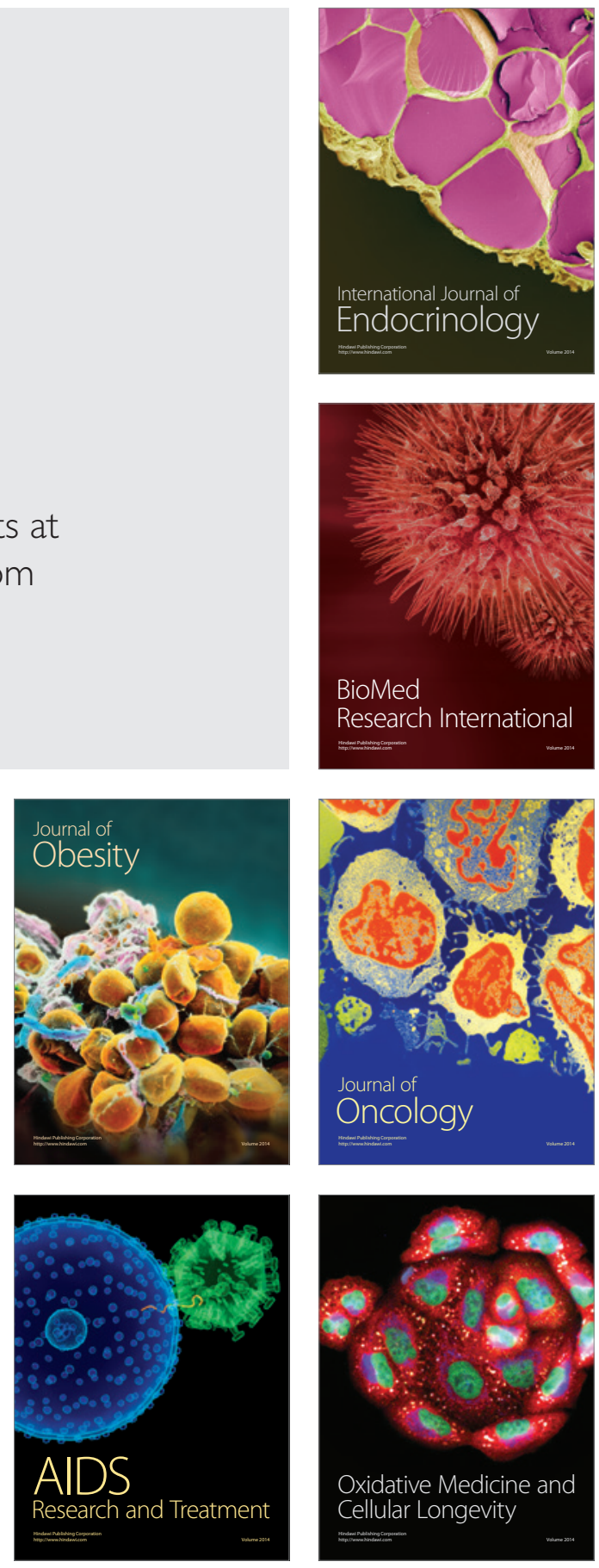